\title{
Peri-hilar branching pattern and variations of the renal artery among Indian kidney donors using pre-operative computed tomography angiography: an anatomical study and review
}

\author{
M. Kumaresan1, J. Saikarthik² (1), A. Sangeetha ${ }^{3}$, I. Saraswathi ${ }^{4}$, K. Senthil Kumar ${ }^{4}$, P. Roselin ${ }^{5}$ \\ ${ }^{1}$ Department of Anatomy, Saveetha Medical College and Hospital, SIMATS University, Chennai, India \\ 2Department of Basic Medical Sciences, Department of Medical Education, College of Dentistry, \\ Majmaah University, Al Zulfi, Riyadh, Kingdom of Saudi Arabia \\ ${ }^{3}$ Department of Physiology, Saveetha Medical College and Hospital, SIMATS University, Chennai, India \\ ${ }^{4}$ Department of Physiology, Madha Medical College and Research Institute, Chennai, India \\ ${ }^{5}$ Department of Radiology and Imaging, Madha Medical College and Research Institute, Chennai, India
}

[Received: 6 August 2021; Accepted: 20 September 2021; Early publication date: 7 October 2021]

Background: The peri-hilar branching pattern of renal arteries and variations such as accessory renal artery and early branching of the renal artery are important factors to be evaluated preoperatively to minimise potential complications during renal transplantation and renal surgeries. The present study was done to assess the peri hilar branching pattern of the renal artery and its variation among the renal donors in India.

Materials and methods: One hundred ninety eight kidneys from 99 donors were analysed using pre-operative computed tomography renal angiograms prospectively, over 1 year 2 months.

Results: Based on the branching pattern of primary and secondary branches of renal arteries, we identified 8 cardinal and 10 minor peri-hilar branching patterns. Type I (duplicated fork) peri-hilar branching pattern was the most frequently found (70.2\%) among 198 kidneys, followed by type II (triplicated fork) (19.2\%) and type III (ladder) (10.6\%). Duplicated fork pattern was common in both the right renal artery (75.7\%) and left renal artery (64.6\%), respectively. The prevalence of accessory renal artery was $39.4 \%$ with hilar artery at $21.2 \%$ and polar artery at $18.2 \%$, and the prevalence of early division of renal artery was $20.2 \%$. No significant association was found between gender and laterality in the prevalence of both early division and accessory renal artery $(p>0.05)$. Early division of renal artery was more frequent in females (28\%) whilst accessory renal arteries were more common in males (40.7\%). Conclusions: The present study showed a consistent peri-hilar branching pattern with high individual variability among Indian renal donors. The knowledge about the peri-hilar branching pattern as well as renal artery variations conferred by this study would greatly compliment urological surgeons during renal transplant surgeries. (Folia Morphol 2022; 81, 4: 971-982)

Key words: peri-hilar, renal, artery, accessory, early, donors, computed tomography

Address for correspondence: Dr. J. Saikarthik, Assistant Professor of Anatomy, Department of Basic Medical Sciences; Department of Medical Education, Majmaah University, Al Zulfi, Kingdom of Saudi Arabia 11952, tel: +966 531272304, e-mail: s.jaya@mu.edu.sa

This article is available in open access under Creative Common Attribution-Non-Commercial-No Derivatives 4.0 International (CC BY-NC-ND 4.0) license, allowing to download articles and share them with others as long as they credit the authors and the publisher, but without permission to change them in any way or use them commercially. 


\section{INTRODUCTION}

India stands $2^{\text {nd }}$, only behind the United States of America, among the living kidney transplantation programme globally. In India, approximately 7500 renal transplants are performed every year with $90 \%$ from live donors and the remaining from deceased donors [27]. Complete evaluation of renal vascular anatomy preoperatively in live donors is essential to predict and manage potential risks and to prevent complications during renal surgeries. Knowledge of renal vascular variation is important in the exploration and treatment of renal trauma, renal transplantation, renal vascular hypertension, and renal artery embolisation [12, 30]. It also enables segmental arterial ligature which greatly reduces damage to renal parenchyma in case of segmental laparoscopic surgeries [31]. Anatomical variations of renal vessels occur in $25 \%$ to $40 \%$ of kidneys. Variations in the renal vessels, including accessory renal artery and early division of renal artery, may be associated with atherosclerosis and renovascular hypertension which are well-established causes of uro-surgical complications [24, 26]. The accessory renal artery is one of the most common variations which needs attention clinically [3, 29].

Various terminologies have been used in the past to describe the branching pattern of renal arteries [31]. Graves (1954) [11] described the segmental branching pattern of the renal artery which has been followed to date. He described that each kidney has five segments, and each renal segment is supplied by an end artery named segmental artery, which arises either from the anterior or posterior division of the main renal artery. The peri-hilar branching pattern has been neglected by Graves's segmental classification of renal arteries. Studying the peri-hilar branching pattern of the renal artery is essential and is being increasingly investigated with advancing radio diagnostic techniques. Studying the morphology and branching pattern of the renal artery helps to avoid potential complications during renal transplantation and renal surgeries. It was also found that there exist ethnic and racial variations in the renal artery branches and branching pattern [14]. However, the literature survey shows very limited studies focussing on the peri-hilar branching pattern of the renal artery.

In India, very few studies have been done to determine the variations of the renal artery and renal artery branching pattern using computed tomography (CT) angiogram in live kidney donors [7, 17]. Globally, very few studies $[25,31]$ regarding the perihilar branch- ing pattern of the renal artery are available while no study has been done in the Indian population. Thus, the present study was undertaken to analyse and classify the peri-hilar branching pattern of the renal artery and to assess the prevalence of accessory renal artery and early division of renal artery among Indian kidney donors.

\section{MATERIALS AND METHODS}

\section{Sample selection}

It has been estimated that the total number of renal transplantations done in live kidney donors in India per year is around 6750 (90\% of 7500) [27]. Using statcalc software, allowing a margin of error at $10 \%$ and confidence interval at $95 \%$, the minimal sample size needed for this study was calculated to be 95 . This was a prospective observational study conducted on renal donors who underwent preoperative renal angiogram in a scan centre in Chennai, India. The study spanned for 1 year 2 months which included the CT renal angiogram of 99 renal donors (54 males and 45 females). All patients included in the study had normal renal functions. Only the angiograms from adults (age $>18$ years) without any renal disease, without pathological conditions likely to affect renal vasculature, and with sufficient enhancement of contrast media in the arterial phase $(150 \mathrm{HU})$ were collected and studied. The study was conducted as per the declaration of Helsinki and ethical approval was obtained from the institutional Human Ethical Committee at Saveetha Institute of Medical and Technical Sciences, Chennai (001/09/2015/IEC/SU).

\section{Multidetector CT and postprocessing}

All donors underwent $\mathrm{CT}$ renal angiogram in $\mathrm{GE}$ systems, 64-slice multidetector CT (MDCT) scanner. The scanning parameters were $120 \mathrm{kV}, 240 \mathrm{mAs}$, and slice thickness of $0.625 \mathrm{~mm}$. The scan area extended from the diaphragm to the iliac crest and images were acquired at a rotational speed of $0.7 \mathrm{~s}$. Using a bolus tracker placed in the abdominal aorta at the level of renal arteries, and with a delay of about 6 to $8 \mathrm{~s}, \mathrm{CT}$ images were acquired in the arterial phase. About $90 \mathrm{~mL}$ non-ionic contrast (Omnipaque ${ }^{\mathrm{TM}}$ ) mixed with $20 \mathrm{~mL}$ saline was injected through the ante-cubital vein using a pressure injector $(5 \mathrm{~mL} / \mathrm{s})$.

The serial thin-section images thus obtained were imported to a dedicated three-dimensional (3D) workstation where they were reconstructed using minimum intensity projection (MIP), multiplanar reforma- 
tion (MPR), and 3D volume rendering (VR) techniques for diagnostic purposes. These techniques allowed for identifying the variant branching pattern of the renal artery as well as for accurate measurement of the renal arteries. All observations and measurements were done by a single observer (radiologist - author R.P.) and the details were recorded.

\section{Classification criteria of renal arterial morphology}

The criteria for the classification of renal arterial morphology used in this study was based on the earlier study by Shoja et al. (2008) [25]. Morphologically, the renal arterial branching patterns were of two types, viz. fork-type and ladder-type. In fork-type, there was a single point of division of the branch which could either be duplicated - type I (upper and lower branch) or triplicated - type II (upper, middle, and lower branch). In ladder-type - type III, there were sequential branching points. We employed a uniform terminology, where the first division of the renal artery was termed as the primary branch and the further divisions were termed as secondary and tertiary branches.

The classification of the peri-hilar branching pattern of the renal artery was done based on both its primary and secondary divisions and their branching patterns. 'Cardinal perihilar renal arterial morphology' included those which had more than or equal to $5 \%$ of the total observed types and the remaining types $(<5 \%)$ were included in the 'minor' category $(\mathrm{m})$. The various subtypes under each of types I, II, and III were arranged in descending order with subtype 'a' indicating the highest prevalence followed by the other subtypes. When two subtypes had the same rate of prevalence, naming was allotted randomly between them following the sequential order.

\section{Variations in renal artery}

Prevalence of early division of renal artery was studied among the study population. When the renal artery length was less than $1.5 \mathrm{~cm}$, it was considered as an early division [6]. The prevalence of accessory renal artery was also studied. The accessory renal artery was classified according to the entry into the kidney as hilar (passes through hilum) and polar renal artery (passes through the upper or lower pole of the kidney).

\section{Statistical analysis}

Descriptive statistics were performed for the obtained data. Chi-square test was used to compare prevalences between gender and laterality. All statistical analysis was performed using SPSS version 21. P value less than 0.05 was taken to be statistically significant.

\section{RESULTS}

The renal artery showed immense variability in its divisions and branching patterns between and within the individuals studied.

\section{Cardinal peri-hilar morphologies of the main renal artery}

A total of 8 cardinal patterns and 10 minor branching patterns of renal arteries were noted in the present study (Table 1, Fig. 1). In a total of 198 kidneys of renal donors who were evaluated, type I-a (duplicated fork) was the most common pattern (16.1\%) and type I-e (duplicated fork with duplicated lower and upper ladder branch) and I-f (duplicated fork with the upper and lower branch ladder pattern) both with $5.5 \%$ was the least common cardinal patterns. Type I-a pattern was also commonly noted in the males on the left side and the females on the right side. Regarding the minor patterns, type $\mathrm{ml}-\mathrm{a}$ (4\%) was the most common, and type ml-e and type $\mathrm{ml}-\mathrm{f}(1 \%)$ was the least common pattern.

Type I peri-hilar branching pattern was the most found (70.2\%) among 198 kidneys, followed by type II (19.2\%) and type III (10.6\%).

\section{The peri-hilar branching pattern}

of the right main renal artery

Fork pattern of branching in the primary branch was observed in $88.9 \%$. The fork was either duplicated $(75.7 \%)$ or triplicated (14.1\%). The ladder-type pattern was observed in $11.1 \%$. In the fork-type primary branches that are given off the main artery, a secondary division was found in $61.6 \%$ that was fork-type in $36.3 \%$, ladder-type in $15.2 \%$, and both fork and ladder in $10.1 \%$ of donors. No secondary branches were noted in the kidneys with ladder-type primary artery. In the majority of donors, the branches of a ladder-type artery were terminal segmental arteries to the renal parenchyma. Only $3.03 \%$ of fork-type secondary divisions were triplicated. Tertiary branches were found in 33 kidneys.

\section{The peri-hilar branching pattern of the left main renal artery}

Fork pattern of branching in the primary branch was observed in $88.8 \%$. The fork was duplicated in $64.6 \%$ and triplicated in $24.2 \%$ of cases. The lad- 
Table 1. Peri-hilar branching pattern of the renal artery

\begin{tabular}{|c|c|c|c|c|c|c|}
\hline \multirow[t]{2}{*}{ Type } & \multirow[t]{2}{*}{ Pattern } & \multirow{2}{*}{$\begin{array}{c}N(\%) \\
\text { (Total } 198 \text { kidneys) }\end{array}$} & \multicolumn{2}{|c|}{ Right } & \multicolumn{2}{|c|}{ Left } \\
\hline & & & Male (54) & Female (45) & Male (54) & Female (45) \\
\hline \multicolumn{7}{|c|}{ Cardinal branching pattern } \\
\hline Type l-a & Duplicated fork & $32(16.1)$ & $9(16.6 \%)$ & $8(17.7 \%)$ & $9(16.6 \%)$ & $6(13.3 \%)$ \\
\hline Type I-b & Duplicated fork with duplicated upper branch & $23(11.6)$ & $8(14.8 \%)$ & $8(17.7 \%)$ & $4(7.4 \%)$ & $3(6.6 \%)$ \\
\hline Type I-c & $\begin{array}{l}\text { Duplicated Fork with upper (u) and lower (I) } \\
\text { branches }\end{array}$ & $21(10.6)$ & $3(5.5 \%)$ & $8(17.7 \%)$ & $3(5.5 \%)$ & $7(15.5 \%)$ \\
\hline Type I-d & $\begin{array}{l}\text { Duplicated fork with upper and lower branch } \\
\text { with the duplicated lower branch }\end{array}$ & $14(7)$ & $3(5.5 \%)$ & Nil & $6(11.1 \%)$ & $5(11.1 \%)$ \\
\hline Type l-e & $\begin{array}{l}\text { Duplicated fork with duplicated lower and upper } \\
\text { ladder branch }\end{array}$ & $11(5.5)$ & $4(7.4 \%)$ & $1(2.2 \%)$ & $5(9.2 \%)$ & $1(2.2 \%)$ \\
\hline Type l-f & $\begin{array}{l}\text { Duplicated fork with the upper and lower branch } \\
\text { ladder pattern }\end{array}$ & $11(5.5)$ & $4(7.4 \%)$ & $2(4.4 \%)$ & $5(9.2 \%)$ & Nil \\
\hline Type II & Triplicated fork pattern & $23(11.6)$ & $7(12.9 \%)$ & $3(6.6 \%)$ & $8(14.8 \%)$ & $5(11.1 \%)$ \\
\hline Type III & Single ladder type & $21(10.6)$ & $5(9.2 \%)$ & $6(13.3 \%)$ & $6(11.1 \%)$ & $4(8.8 \%)$ \\
\hline \multicolumn{7}{|c|}{ Minor branching pattern } \\
\hline Type ml-a & Duplicated fork with triplication of upper branch & $8(4)$ & $1(1.8 \%)$ & $2(4.4 \%)$ & $2(3.7 \%)$ & $3(6.6 \%)$ \\
\hline Type ml-b & $\begin{array}{l}\text { Duplicated fork with duplicated upper and lower } \\
\text { ladder branch }\end{array}$ & $6(3)$ & $1(1.8 \%)$ & $1(2.2 \%)$ & Nil & $4(8.8 \%)$ \\
\hline Type ml-c & Duplicated fork with upper ladder pattern & $5(2.5)$ & $2(3.7 \%)$ & $3(6.6 \%)$ & Nil & Nil \\
\hline Type ml-d & Duplicated fork with lower ladder pattern & $4(2)$ & $3(5.5 \%)$ & $1(2.2 \%)$ & Nil & Nil \\
\hline Type ml-e & $\begin{array}{l}\text { Duplicated fork with triplicated upper and } \\
\text { duplicated lower branch }\end{array}$ & $2(1)$ & Nil & $1(1.8 \%)$ & Nil & $1(1.8 \%)$ \\
\hline Type ml-f & $\begin{array}{l}\text { Duplicated fork with upper ladder and lower } \\
\text { triplicated pattern }\end{array}$ & $2(1)$ & $2(3.7 \%)$ & Nil & Nil & Nil \\
\hline Type mll-a & Triplicated fork with duplicated middle branch & $5(2.5)$ & Nil & $2(4.4 \%)$ & $1(1.8 \%)$ & $2(4.4 \%)$ \\
\hline Type mll-b & $\begin{array}{l}\text { Triplicated fork with duplication of upper and } \\
\text { middle branch }\end{array}$ & $4(2)$ & Nil & Nil & $2(3.7 \%)$ & $2(4.4 \%)$ \\
\hline Type mll-c & Triplicated fork with duplication of lower branch & $3(1.5)$ & $2(3.7 \%)$ & Nil & $1(1.8 \%)$ & Nil \\
\hline Type mll-d & $\begin{array}{l}\text { Triplicated fork with ladder pattern in upper and } \\
\text { lower branch }\end{array}$ & $3(1.5)$ & Nil & Nil & $3(6.6 \%)$ & Nil \\
\hline
\end{tabular}

der-type pattern was observed in $10.1 \%$. In the forktype primary branches that were given off the main artery, a secondary division was found in $61.6 \%$ that was fork-type in $44.4 \%$, ladder-type in $7.0 \%$, and both fork and ladder in $10.2 \%$ of donors. No secondary branches were noted in the kidneys with ladder-type primary artery. In the majority of donors, the branches of a ladder-type artery were terminal segmental arteries to the renal parenchyma. Only $5.05 \%$ of fork-type secondary divisions were triplicated. Tertiary branches were found in 35 kidneys.

\section{Early division of renal artery}

The early division was noted among 7 males (out of 54) and 13 (out of 45) females (including both unilateral and bilateral early division). The overall prevalence was $20.2 \%$. Statistical analysis revealed no association between gender and laterality in the prevalence of early division of renal arteries $(p=0.08$; Table 2). An angiographic image of the early division of the renal artery is shown in Figure 2.

\section{Accessory renal arteries}

Of the total 99 donors, the occurrence of the accessory renal artery was seen in 39 (39.4\%) donors (including the unilateral and bilateral presence of accessory renal artery). Out of 39 observed accessory renal arteries, 38 single accessory renal arteries and a single case of multiple accessory renal arteries were observed. Statistical analysis showed no association between gender and laterality in the prevalence of accessory renal arteries ( $p=0.9$; Table 3 ). 


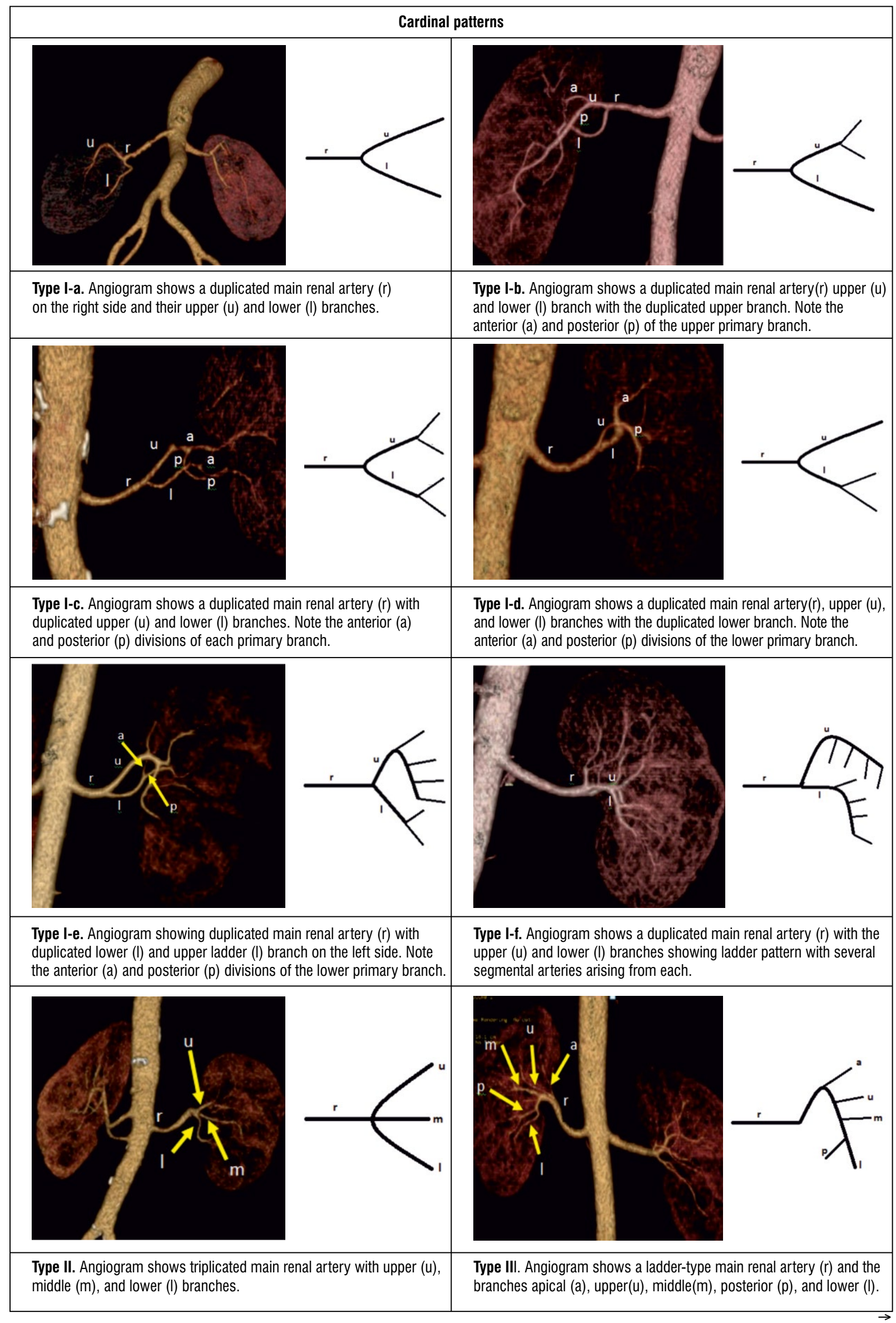




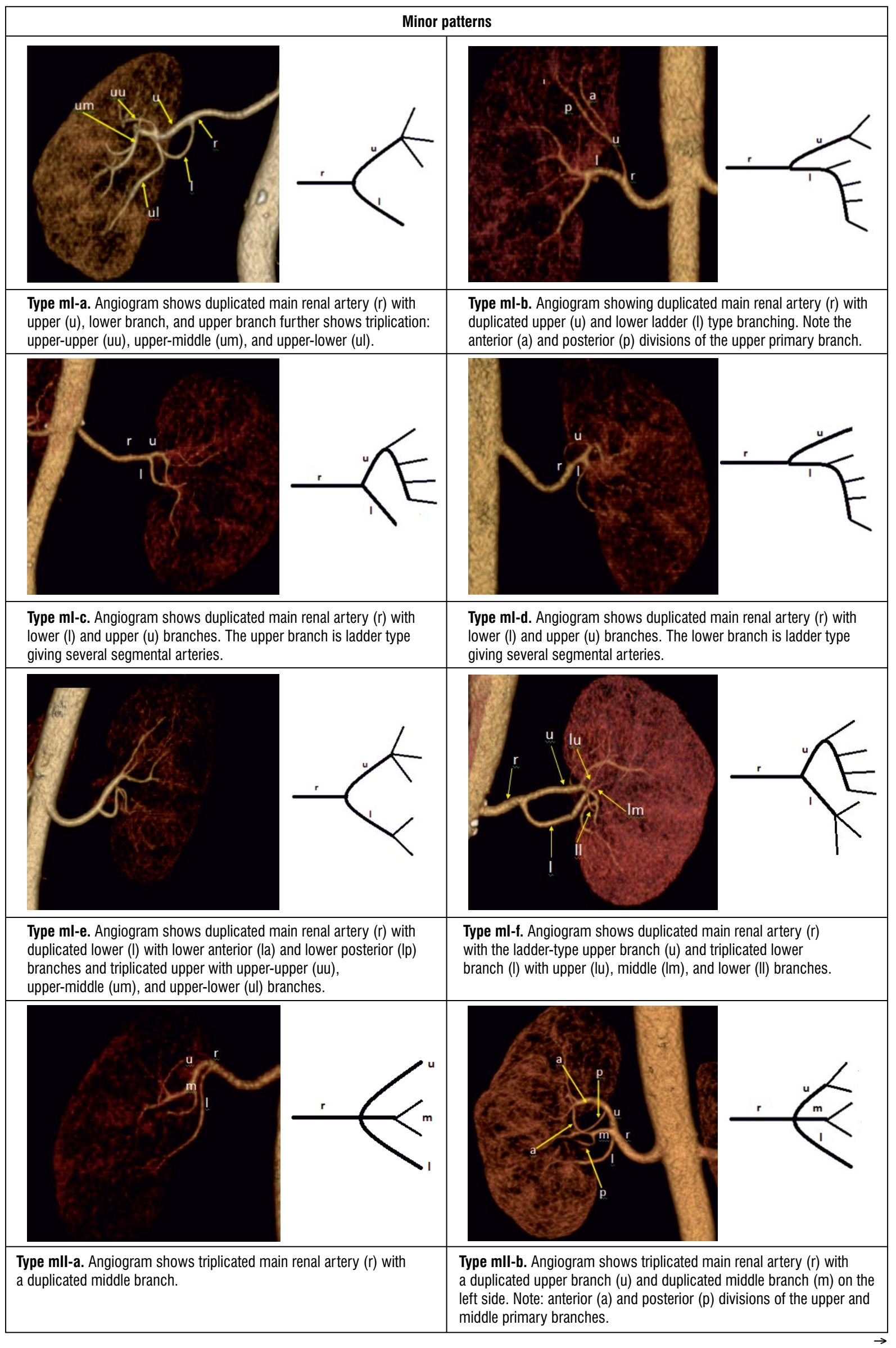




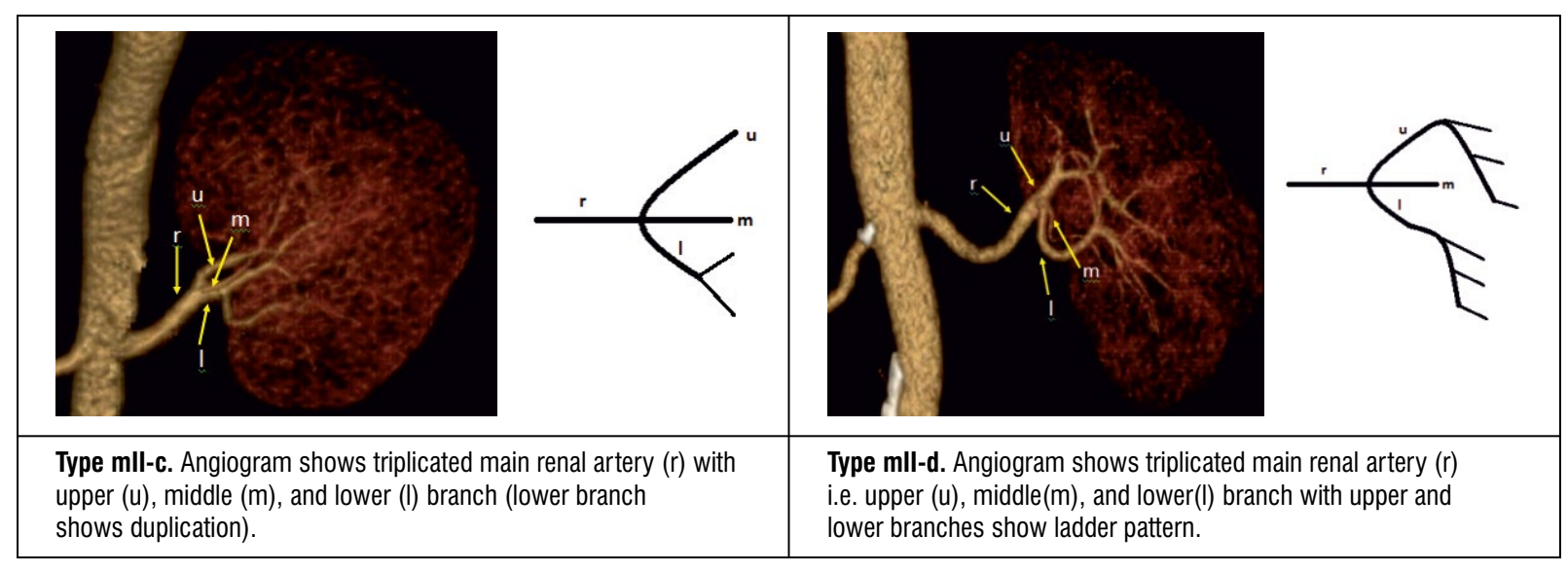

Figure 1. Representative computed tomography-angiogram images with schematic diagrams of cardinal ( $>5 \%$ prevalence) and minor $(<5 \%$ prevalence) peri-hilar branching patterns noted in the present study; type I — duplicated fork, type II — triplicated fork, type III — ladder-type were the main types of patterns. These patterns were divided into sub-patterns as indicated alphabetically. Note that minor patterns are indicated by ' $m$ ' as the prefix.

Table 2. Early division of renal artery

\begin{tabular}{lccc}
\hline Early division of renal artery & Male $(\mathbf{n}=\mathbf{5 4}) ; \mathbf{7 / 5 4}(\mathbf{1 3} \%)$ & Female $(\mathbf{n}=\mathbf{4 5}) ; \mathbf{1 3} / \mathbf{4 5}(\mathbf{2 8} \%)$ & Chi square test \\
\hline Right $(\mathrm{n}=99)$ & $1(1.8 \%)$ & $7(15.5 \%)$ & $\chi^{2}=2.937$ \\
Left $(\mathrm{n}=99)$ & $6(11.1 \%)$ & $6(13.3 \%)$ & $\mathrm{P}=0.087$ \\
\hline
\end{tabular}

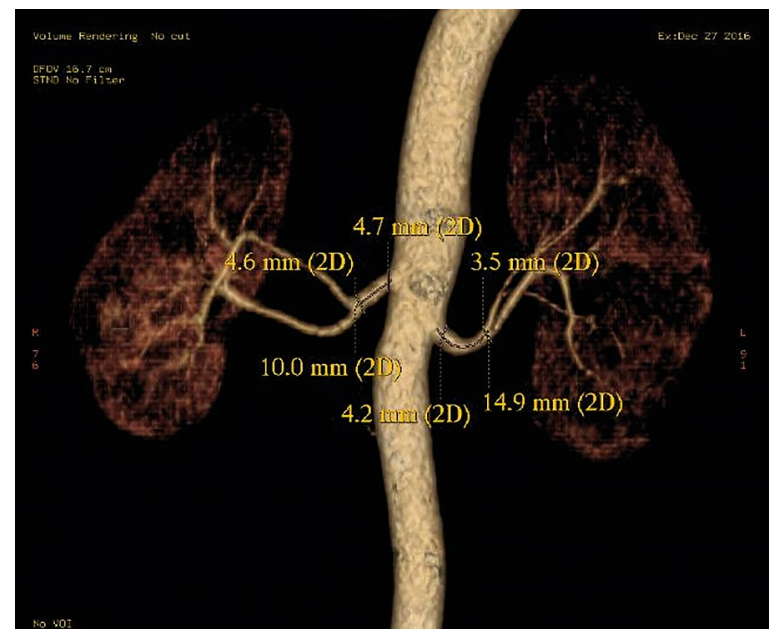

Figure 2. Early division of renal artery on the right side $(0.47 \mathrm{~cm})$ and left side $(0.35 \mathrm{~cm}) ; 2 \mathrm{D}$ - two-dimensional measurements.

The accessory renal artery was further classified as hilar and polar arteries. Donors with hilar and polar accessory renal arteries were $21(21.2 \%)$ and 18 $(18.2 \%)$, respectively. The occurrence of the polar renal artery is given in Table 4 and its images are shown in Figures 3-6. Females had a higher prevalence of polar artery $(n=12)$ when compared to males $(n=6)$. However, statistical tests revealed no association between gender and laterality in the prevalence of polar renal arteries in the population $(p=0.218)$.

\section{DISCUSSION}

Routine preoperative evaluation of donors undergoing total or partial nephrectomy and renal transplant compels knowledge of the peri-hilar branching pattern of the renal artery and other renal artery variations like accessory renal artery and early division of renal artery through various imaging techniques. The present study, despite finding predictable morphology in the peri-hilar branching pattern of renal artery, also noted high individual variability in the same. Though the study was based on the classification criteria by Shoja et al. [25] there were major differences between the results of the two studies. Even though the number of cardinal (8 types) and minor branching pattern (10 types) types were the same, the patterns found in the present study did not match with that of Shoja et al. [25]. Though few studies have described the peri-hilar branching pattern in renal artery morphology, most of them 
Table 3. Occurrence of accessory renal artery

\begin{tabular}{|c|c|c|c|c|c|c|c|}
\hline \multirow{3}{*}{$\begin{array}{l}\text { The occurrence } \\
\text { of accessory renal } \\
\text { artery (ARA) }\end{array}$} & \multicolumn{6}{|c|}{ Total (39) (39.4\%) } & \multirow{3}{*}{$\begin{array}{c}\text { Chi-square } \\
\text { test }\end{array}$} \\
\hline & \multicolumn{2}{|c|}{ Right; 13/99 (13.1\%) } & \multicolumn{2}{|c|}{ Left; 17/99 (17.2\%) } & \multicolumn{2}{|c|}{ Both sides; 9/99 (9.1\%) } & \\
\hline & Male & Female & Male & Female & Male & Female & \\
\hline Single ARA & $8(14.8 \%)$ & $5(11.1 \%)$ & $9(16.6 \%)$ & $8(17.7 \%)$ & $4(7.4 \%)$ & $4(8.8 \%)$ & $\chi^{2}=0.009$ \\
\hline Multiple ARA & Nil & Nil & Nil & Nil & $1(1.8 \%)$ & Nil & $P=0.925$ \\
\hline
\end{tabular}

Table 4. Occurrence of polar renal artery

\begin{tabular}{lcccc}
\hline Polar renal artery & $\begin{array}{c}\text { Total (18) } \\
(\mathbf{1 8 . 2 \% )}\end{array}$ & $\begin{array}{c}\text { Male }(\mathrm{n=54)} \mathbf{6} / \mathbf{5 4} \\
(\mathbf{1 1 . 1 \% )}\end{array}$ & $\begin{array}{c}\text { Female }(\mathrm{n}=\mathbf{4 5}) \mathbf{1 2} / \mathbf{4 5} \\
\mathbf{( 2 6 . 6 \% )}\end{array}$ & $\begin{array}{c}\text { Chi-square } \\
\text { test }\end{array}$ \\
\hline $\begin{array}{l}\text { Right: } \\
\text { Upper }\end{array}$ & 3 & $2(3.7 \%)$ & $1(2.2 \%)$ & \\
$\quad$ Lower & 3 & $1(1.8 \%)$ & $2(4.4 \%)$ & $\chi^{2}=1.528$ \\
Left: & & & & \\
Upper & 9 & $3(5.5 \%)$ & $6(13.3 \%)$ & 0.218 \\
Lower & 3 & $0(0 \%)$ & $3(6.6 \%)$ & \\
\hline
\end{tabular}

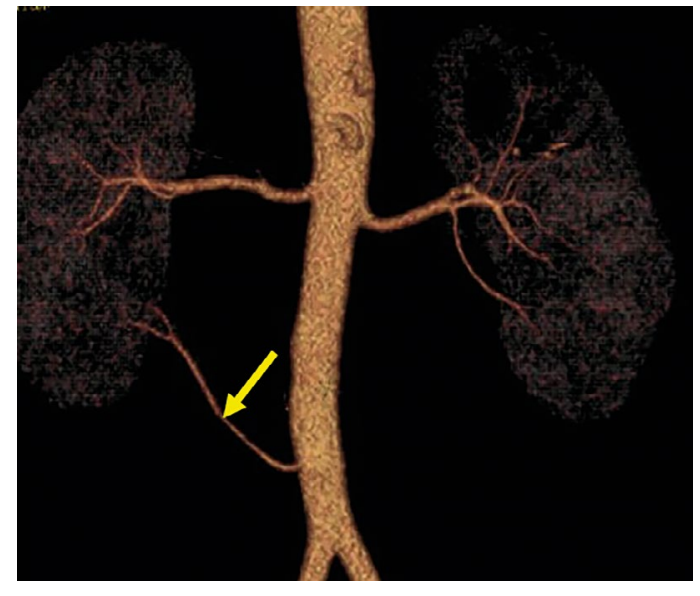

Figure 3. Right single lower polar renal artery.

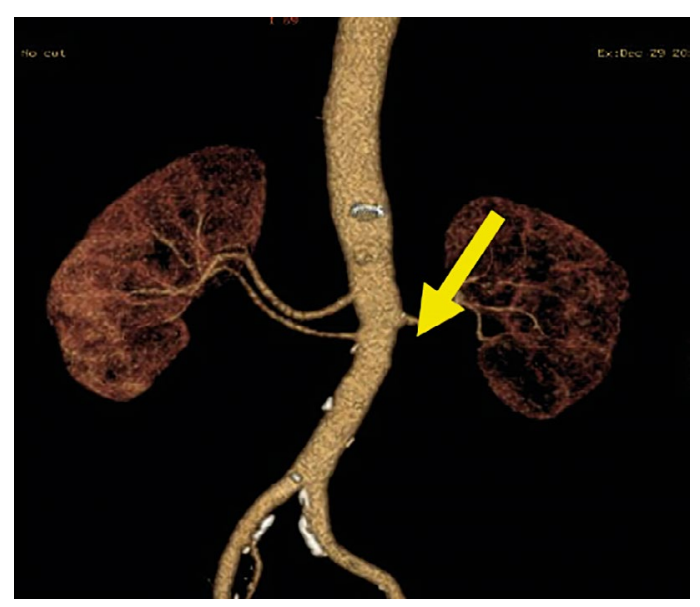

Figure 5. Single accessory on right side entering hilum.

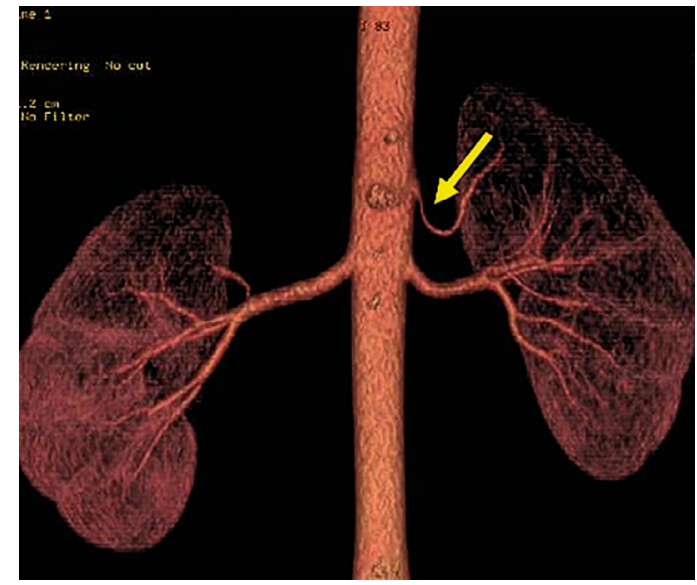

Figure 4. Left single upper polar renal artery.

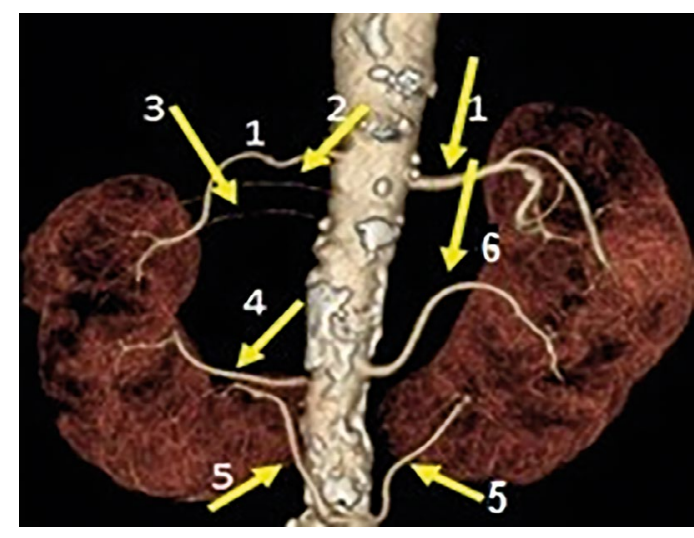

Figure 6. Multiple bilateral accessory arteries; 1, 2, 3- upper accessory renal arteries; 4 and 6 - right and left renal arteries; 5 - lower accessory renal arteries. 
Table 5. Comparison of peri-hilar branching patterns from the present study with the only available earlier studies of Shoja et al. (2008) [25] and Vahed et al. (2020) [31]. Note that the subtypes mentioned in the table are the nomenclature used in this study. (Types I, II, III are cardinal patterns and type $\mathrm{ml}$, mll are minor patterns.)

\begin{tabular}{|c|c|c|c|c|c|c|c|c|c|c|c|c|c|c|c|c|c|c|}
\hline Study & $\begin{array}{l}\text { Type } \\
\text { I-a } \\
(\%)\end{array}$ & $\begin{array}{c}\text { Type } \\
\text { I-b } \\
(\%)\end{array}$ & $\begin{array}{l}\text { Type } \\
\text { I-c } \\
(\%)\end{array}$ & $\begin{array}{c}\text { Type } \\
\text { I-d } \\
\text { (\%) }\end{array}$ & $\begin{array}{l}\text { Type } \\
\text { I-e } \\
(\%)\end{array}$ & $\begin{array}{c}\text { Type } \\
\text { I-f } \\
(\%)\end{array}$ & $\begin{array}{c}\text { Type } \\
\text { II } \\
(\%)\end{array}$ & $\begin{array}{c}\text { Type } \\
\text { III } \\
(\%)\end{array}$ & $\begin{array}{c}\text { Type } \\
\text { ml-a } \\
(\%)\end{array}$ & $\begin{array}{c}\text { Type } \\
\text { ml-b } \\
\text { (\%) }\end{array}$ & $\begin{array}{c}\text { Type } \\
\text { ml-c } \\
(\%)\end{array}$ & $\begin{array}{c}\text { Type } \\
\text { ml-d } \\
\text { (\%) }\end{array}$ & $\begin{array}{c}\text { Type } \\
\text { ml-e } \\
(\%)\end{array}$ & $\begin{array}{l}\text { Type } \\
\text { ml-f } \\
\text { (\%) }\end{array}$ & $\begin{array}{c}\text { Type } \\
\text { mll- a } \\
(\%)\end{array}$ & $\begin{array}{c}\text { Type } \\
\text { mll- b } \\
(\%)\end{array}$ & $\begin{array}{c}\text { Type } \\
\text { mll-c } \\
(\%)\end{array}$ & $\begin{array}{c}\text { Type } \\
\text { mll-d } \\
(\%)\end{array}$ \\
\hline $\begin{array}{l}\text { Present study } \\
(\mathrm{n}=198)\end{array}$ & 16.1 & 11.6 & 10.6 & 7 & 5.5 & 5.5 & 11.6 & 10.6 & 4 & 3 & 2.5 & 2 & 1 & 1 & 2.5 & 2 & 1.5 & 1.5 \\
\hline $\begin{array}{l}\text { Shoja et al., } 2008 \\
(\mathrm{n}=81)\end{array}$ & 8.6 & 16.1 & 23.5 & 3.7 & 7.4 & 2.5 & - & 7.4 & 1.2 & 7.4 & - & 6.2 & 2.5 & - & 6.2 & 1.2 & - & - \\
\hline $\begin{array}{l}\text { Vahed et al., } 2020 \\
(\mathrm{n}=255)\end{array}$ & 0.8 & 0.8 & 2 & - & 18.4 & 14 & - & 5 & 2.4 & 11.8 & - & 2.7 & 3.1 & - & 0.8 & 5.1 & - & - \\
\hline
\end{tabular}

had confusing terms while plain and simple terminology to describe the branches remains to be in scarcity (Table 5). According to Weld et al. [33], the main branch from the renal artery was named as pre-segmental artery and the subsequent branches were named as segmental arteries which enter the renal parenchyma. Their classification included three main branching patterns viz. configurations without a pre-segmental branch, with one pre-segmental branch, and with two pre-segmental branches. The classification by Graves (1954) [11] has been widely accepted, where kidneys were divided into five vascular segments and segmental independent blood supply with no collateral circulation. However, few studies have suggested three to five segments [2, 23]. Fine and Keen [9] introduced the concept of three primary renal arteries and based on the first arriving primary renal artery, there were four branching patterns. They also introduced three branching patterns for posterior vessels viz. magistral, cruciate and bifurcating. Most of the studies conducted in India were cadaveric studies with a handful of studies based on imaging techniques. In addition, all the studies analysing the renal artery branching pattern in the Indian population followed the nomination by Graves (1954) [11] and Welt et al. [33], where the main branches of the renal artery were named anterior and posterior division and each division further divide or forms pre-segmental or segmental arteries. Kumar and Prabha (2016) [16] studied the pre-hilar branching pattern in human cadavers. Their results were comparable with earlier studies by Graves [11], Fine and Keen [9], Verma et al. [32], and Kher et al. [15], in which, based on the branching of anterior division, there were three types, and based on that of posterior division there were two types. A study conducted using MDCT angiography found the posterior division continuing as segmental artery and based on the branching of anterior division, they were classified in to nine types [7]. In contrast to these studies, the present study used the nomination of naming the first division of renal artery as the primary branch and subsequent divisions as secondary and tertiary branches and based on the arterial branching pattern, there were two patterns viz. the fork type and ladder type. To our knowledge, the present study is the first of its kind to analyse the peri-hilar branching pattern of the renal artery and to develop a classification based on that in the Indian population. Globally, only a handful of studies have done the same. A couple of studies followed the same nomination of branching pattern $[25,31]$ while the remaining followed the one by Graves [11] and Weld et al. [33]. Thus, studies analysing peri-hilar branching patterns are in scarcity both in India and globally. Variations in the renal vasculature may occur within different populations and hence must be taken into account during preoperative surgical examination of kidneys. Thus, the results of the present study would serve as important guideline in urological surgical procedures.

In the present study, early division of the main renal artery was found in $20.2 \%$ of the subjects with $8.1 \%$ on the right side and $12.1 \%$ on the left side. The prevalence of early division of renal artery varies drastically in different studies conducted across various populations. In a study conducted by Ozkan et al. [20], in Turkey, early division of renal artery was noted in $8 \%$ of cases. $21.6 \%$ of cases showed pre-hilar branching of the renal artery in the Kenyan population [19]. Another study observed early division in $33.3 \%$ and $28.5 \%$ of cases in the right and left kidneys respectively [4]. Dogra et al. [7] observed an early division of renal artery among $25 \%$ of a total of 200 
Table 6. List of important previous literature on early division of renal artery

\begin{tabular}{|c|c|c|c|c|c|}
\hline \multirow[t]{2}{*}{ Study } & \multirow[t]{2}{*}{ Population } & \multirow[t]{2}{*}{ Method } & \multirow[t]{2}{*}{ Sample size } & \multicolumn{2}{|c|}{ Early division of renal artery } \\
\hline & & & & Right side & Left side \\
\hline Ozkan et al. (2006) [20] & Turkey & Angiography & 855 & $32 \%$ & $25 \%$ \\
\hline Ogeng'o et al. (2010) [19] & Kenya & Cadaver & 178 & $16.2 \%$ & $26 \%$ \\
\hline Budhiraja et al. (2013) [4] & India & Cadaver & 42 & $33.3 \%$ & $28.5 \%$ \\
\hline Dogra et al. (2017) [7] & India & CTA & 100 & $27 \%$ & $23 \%$ \\
\hline Famurewa et al. (2018) [8] & Nigeria & CTA & 200 & $4 \%$ & $0.5 \%$ \\
\hline Ahmed et al. (2019) [1] & Egypt & $\begin{array}{c}\text { CTA } \\
\text { and specimens }\end{array}$ & $\begin{array}{c}100 \text { (CTA), } \\
7 \text { kidneys (specimens) }\end{array}$ & - & $3 \%$ \\
\hline Present study & India & CTA & 198 & $8.1 \%$ & $12.1 \%$ \\
\hline
\end{tabular}

CTA — computed tomography angiography

renal arteries. Natsis et al. [18] found early division in $30.4 \%$ of cases. Most of these studies have not clearly mentioned the specific distance to recognise early division while some have considered $2 \mathrm{~cm}$ from hilum as the reference point. However, the current study followed the well-recognised interval of $1.5 \mathrm{~cm}$ from the aorta as specified in the literature for identifying the early division of the renal artery [6]. Previous studies analysing the early division of the renal artery are given in Table 6 .

We found no significant gender difference in the occurrence of the early division of renal artery (female $28 \%$ and male $13 \%$ ). Our results are contradictory to the study by Cinar and Turkvatan [6] in Turkey and Famurewa et al. [8] in Nigeria who found that renal vascular variations including early division of renal artery to be significantly higher in males than females. Similar to our results, Palmieri et al. [21] found no significant gender difference in the prevalence of early division of renal artery in the Brazilian population. We also did not find any significant difference between the right and the left side in the prevalence of early division of renal artery in the present study. To our knowledge, studies assessing the association of early renal artery division between gender and laterality are less. It was found that early division to be more common on the right side [8]. In a study done by Budhiraja et al. [4], the early division was found in $61.8 \%$ of cases $(33.3 \%$ on the right side and $28.5 \%$ on the left side). In this study, early division of the renal artery was higher on the left side albeit a lack of statistical significance which is similar to a study conducted in India that reported early division in 5\% on the right side and $7 \%$ on the left side [17]. The difference in ethnicity and population could be the possible reason for the results in the present study.
The significance of early division is important as expert surgeons require at least 1 to $1.5 \mathrm{~cm}$ of the main renal artery to clamp and properly anastomose the artery in the recipient.

In the current study, 39.4\% of donors had accessory renal arteries. We observed a single accessory renal artery in 38 donors and more than two accessory renal arteries were seen in one donor. Single accessory renal artery on the right side was seen in $13.1 \%$ and on the left in $17.2 \%$ and bilateral single accessory was seen in $9.1 \%$ of individuals. A hilar artery was found in $21.2 \%$ and a polar artery was found in $18.2 \%$ of cases. There was no association between the prevalence of both accessory renal artery and polar artery with laterality or gender $\left(\chi^{2}=0.009 ; p=0.925\right.$, $\chi^{2}=1.528 ; p=0.218$ ). In general, the prevalence of accessory renal artery was comparatively higher in males than females and higher on the left side than on the right side though it was not statistically significant. This is contrary to the study done in western India [13] which found a higher incidence of accessory artery on the right side (27.35\%) than on the left side (22.36\%) while being similar to studies by Gag and du Plessis [10]. In the present study, polar arteries were more common on the left side. Association between gender and the prevalence of polar artery was also not statistically significant, $12.1 \%$ of females and $6.1 \%$ of males had polar artery, respectively. The occurrence of the upper polar artery was found to be higher than that of the lower polar artery. Similar results were found in the studies by Jamkar et al. [13] while Sykes [28] found lower polar arteries to be more common. In our study, $12.1 \%$ was the prevalence of the upper polar artery while Budhiraja et al. [5] found it to be $10.7 \%$ and Sampaio and Passos [22] found it to be $6.8 \%$. 
The variations in renal artery vasculature can be elucidated by the development of mesonephric arteries. These arteries supply the kidneys, suprarenal glands, and gonads on either side of the aorta, from the sixth cervical vertebra to the third lumbar vertebra. As the foetus develops most of these arteries disappear, leaving one prominent mesonephric artery. The existence of one or multiple accessory renal arteries is due to the non-obliteration of mesonephric arteries. Such subjects with accessory renal arteries are not ideal candidates for transplantation. Multiple renal arteries have major clinical importance because overlooking them during preoperative preparations of patients for surgical procedure occurs especially if laparoscopic methods are used. Transplantation of kidneys with vascular variations is usually associated with a higher rate of failure. In surgical terms, the upper pole artery represents a major risk because it is frequently located high up the kidney, that in most cases the surgeons may mistake it for surrounding connective tissue. In addition, transplantation of kidneys with polar vessels is deemed to have a higher primary failure rate due to the development of the complication of renal vascular thrombosis [5].

\section{Strengths and limitations of the study}

The current study is the first to analyse the perihilar branching pattern of the renal artery and devise a classification using $\mathrm{CT}$ angiography in renal donors. The study also provides valuable insight into the prevalence of renal artery variations like early division of renal artery and accessory renal artery in renal donors. Despite a limited sample size of 198 kidneys, the results of the study would help the surgeons to better plan appropriate surgical procedures and avoid complications.

\section{CONCLUSIONS}

The peri-hilar branching pattern of the renal artery not only varied between subjects but also between the two sides within the subjects. However, there were predictable branching patterns observed which were classified in to eight major types and minor types based on their frequency. The prevalence of renal artery variations like early division of renal artery and accessory renal artery in the south Indian population was $20.2 \%$ and $39.4 \%$, respectively which showed no significant association with gender or side. The present study will help the readers to better comprehend the complex nature of renal vasculature. This study suggests that a thorough and in-depth understanding of anatomical variations of the renal artery and peri-hilar branching pattern will be helpful in a precise surgical approach to avoid any complications during renal transplantation and other renal surgeries.

\section{Acknowledgements}

The authors would like to thank the deanship of Scientific Research, Majmaah University for the support of this research work.

\section{Conflict of interest: None declared}

\section{REFERENCES}

1. Ahmed S, Al-Moatasem-Bellah M, Farid EF, et al. Variations in renal artery in egyptian population: cadaveric and angiographic study. Med J Cairo University. 2019; 87(June): 1593-1603, doi: 10.21608/mjcu.2019.53579.

2. Ajmani $\mathrm{ML}$, Ajmani $\mathrm{K}$. To study the intrarenal vascular segments of human kidney by corrosion cast technique. Anat Anz. 1983; 154(4): 293-303.

3. Bergman RA, Thompson SA, Afifi AK. Catalog of human variation. Urban \& Schwarzenberg 1984.

4. Budhiraja V, Rastogi R, Anjankar V, et al. Supernumerary renal arteries and their embryological and clinical correlation: a cadaveric study from north India. ISRN Anat. 2013; 2013: 405712, doi: 10.5402/2013/405712, indexed in Pubmed: 25938099.

5. Budhiraja V, Rastogi R, Asthana AK. Variant origin of superior polar artery and unusual hilar branching pattern of renal artery with clinical correlation. Folia Morphol. 2011; 70(1): 24-28, indexed in Pubmed: 21604249.

6. Çınar C, Türkvatan A. Prevalence of renal vascular variations: Evaluation with MDCT angiography. Diagn Interv Imaging. 2016; 97(9): 891-897, doi: 10.1016/j. diii.2016.04.001, indexed in Pubmed: 27178758.

7. Dogra A, Kaundal AP, Chauhan R. Variations in the branching pattern of segmental renal arteries on 64 slice MDCT. J Med Sci Clin Res. 2017; 5(6): 22885-22892, doi: 10.18535/jmscr/v5i6.14.

8. Famurewa OC, Asaleye CM, Ibitoye $\mathrm{BO}$, et al. Variations of renal vascular anatomy in a nigerian population: A computerized tomography studys. Niger J Clin Pract. 2018; 21(7): 840-846, doi: 10.4103/njcp.njcp_237_17, indexed in Pubmed: 29984713.

9. Fine $\mathrm{H}$, Keen EN. The arteries of the human kidney. J Anat. 1966; 100(Pt 4): 881-894, indexed in Pubmed: 5969982.

10. Gag D, du Plessis DJ. Lee McGregor's synopsis of Surgical Anatomy. Bristol John Wright Sons LTD 1986.

11. Graves FT. The anatomy of the intrarenal arteries and its application to segmental resection of the kidney. $\mathrm{Br} J$ Surg. 1954; 42(172): 132-139, doi: 10.1002/bjs.18004217204, indexed in Pubmed: 13209036.

12. Güven $K$, Acunaş B. Multidetector computed tomography angiography of the abdomen. Eur J Radiol. 2004; 52(1): 44-55, doi: 10.1016/j.ejrad.2004.03.032, indexed in Pubmed: 15380846.

13. Jamkar AA, Khan B, Joshi DS. Anatomical study of renal and accessory renal arteries. Saudi J Kidney Dis Transpl. 
2017; 28(2): 292-297, doi: 10.4103/1319-2442.202760, indexed in Pubmed: 28352010.

14. Kadir S, Brothers MF. Atlas of normal and variant angiographic anatomy. WB Saunders Company 1981.

15. Kher GA, Bhargava I, Makhni FS. Intrarenal branching of the renal artery. Ind J Surg. 1960; 22: 563-579.

16. Kumar U, Prabha R. Study of prehilar branching pattern of renal artery in human cadaveric kidneys. Natl J Clin Anat. 2016; 5(2): 86, doi: 10.4103/2277-4025.298192.

17. Munnusamy K, Kasirajan SP, Gurusamy K, et al. Variations in branching pattern of renal artery in kidney donors using CT angiography. J Clin Diagn Res. 2016; 10(3): AC01-AC03, doi: 10.7860/JCDR/2016/16690.7342, indexed in Pubmed: 27134847.

18. Natsis K, Paraskevas G, Panagouli E. A morphometric study of multiple renal arteries in Greek population and a systematic review. Rom J Morphol Embryol. 2014; 55(3 Suppl): 1111-1122.

19. Ogeng'o JA, Masaki CO, Sinkeet SR, et al. Variant anatomy of renal arteries in a Kenyan population. Ann Transplant. 2010; 15(1): 40-45.

20. Ozkan U, Oğuzkurt L, Tercan F, et al. Renal artery origins and variations: angiographic evaluation of 855 consecutive patients. Diagn Interv Radiol. 2006; 12(4): 183-186, indexed in Pubmed: 17160802.

21. Palmieri BJ, Petroianu A, Silva LC, et al. Study of arterial pattern of 200 renal pedicle through angiotomography. Rev Col Bras Cir. 2011; 38(2): 116-121, doi: 10.1590/s010069912011000200009, indexed in Pubmed: 21710050.

22. Sampaio FJ, Passos MA. Renal arteries: anatomic study for surgical and radiological practice. Surg Radiol Anat. 1992; 14(2): 113-117, doi: 10.1007/BF01794885, indexed in Pubmed: 1641734.

23. Sapte E, Bordei P. [Anatomical considerations on the renal arterial segmentation]. Rev Med Chir Soc Med Nat lasi. 2005; 109(3): 597-602, indexed in Pubmed: 16607757.

24. Shakeri AB, Tubbs RS, Shoja MM, et al. Bipolar supernumerary renal artery. Surg Radiol Anat. 2007; 29(1): 89-92, doi: 10.1007/s00276-006-0158-0, indexed in Pubmed: 17061029 .

25. Shoja MM, Tubbs RS, Shakeri A, et al. Peri-hilar branching patterns and morphologies of the renal artery: a review and anatomical study. Surg Radiol Anat. 2008; 30(5): 375-382, doi: 10.1007/s00276-008-0342-5, indexed in Pubmed: 18368282.

26. Shoja MM, Tubbs RS, Shakeri $A B$, et al. Origins of the gonadal artery: embryologic implications. Clin Anat. 2007; 20(4): 428-432, doi: 10.1002/ca.20438, indexed in Pubmed: 17109441.

27. Shroff S. Current trends in kidney transplantation in India. Indian J Urol. 2016; 32(3): 173-174, doi: 10.4103/09701591.185092, indexed in Pubmed: 27555672.

28 . Sykes $D$. The arterial supply of the human kidney with special reference to accessory renal arteries. Br J Surg. 1963; 50: 368-374, doi: 10.1002/bjs.18005022204, indexed in Pubmed: 13979763.

29. Tarzamni MK, Nezami N, Rashid RJ, et al. Anatomical differences in the right and left renal arterial patterns. Folia Morphol. 2008; 67(2): 104-110, indexed in Pubmed: 18521808.

30. Urban BA, Ratner LE, Fishman EK. Three-dimensional volume-rendered CT angiography of the renal arteries and veins: normal anatomy, variants, and clinical applications. Radiographics. 2001; 21(2): 373-386, doi: 10.1148/radiographics.21.2.g01 mr19373, indexed in Pubmed: 11259702.

31. Vahed SZ, Asadi Y, Farnood F, et al. The pattern of peri-hilar and hilar arterial branching in kidney allografts of living donors. J Renal Inj Prev. 2020; 10(3): e23-e23, doi: 10.34172/jrip.2021.23.

32. Verma M, Chaturvedi RP, Pathak RK. Anatomy of renal vascular segments. J Anat Soc. 1961; 10: 12-14.

33. Weld KJ, Bhayani SB, Belani J, et al. Extrarenal vascular anatomy of kidney: assessment of variations and their relevance to partial nephrectomy. Urology. 2005; 66(5): 985-989, doi: 10.1016/j.urology.2005.05.023, indexed in Pubmed: 16286108. 